\title{
Psoriatic arthritis among Egyptian patients with psoriasis attending the dermatology clinic: prevalence, comorbidities, and clinical predictors
}

\author{
Ayman El-Garf ${ }^{1}$, Doaa Ahmed Teleb ${ }^{1}$, Eman R. Said ${ }^{2}$, Mervat Eissa ${ }^{1}$ ID \\ ${ }^{1}$ Rheumatology Department, Cairo University, Egypt \\ ${ }^{2}$ Dermatology Department, Cairo University, Egypt
}

\begin{abstract}
Objectives: Early diagnosis and treatment of psoriatic arthritis (PsA) help to prevent progressive joint involvement and disabilities. There is a problem in the early diagnosis of PsA worldwide, which may be attributed to the dermatologists missing PsA symptoms and signs and a lack of effective screening tools.

Aim of the study: The current study was designed to assess the prevalence, comorbidities, and clinical predictors associated with the development of PsA in psoriasis patients.

Material and methods: A cross-sectional observational study was performed. Screening questionnaires - the Psoriasis Epidemiology Screening Tool (PEST) and Early Arthritis for Psoriatic Patients (EARP) - were applied to 200 psoriasis patients; among them $n=22$ (11\% of all tested patients) were in developmental age. Those with positive questionnaires were classified as having PsA or not according to the classification for psoriatic arthritis criteria. Body surface area, psoriasis area and severity index, and psoriasis disability index tools were used for assessing psoriasis patients. A full rheumatological and dermatological evaluation were carried out for PsA patients.

Results: The prevalence of PsA was found to be $30 \%$, with a mean age of $45.48 \pm 10.79$ years. Further, psoriasis preceded the onset of PSA in 46 patients (76.6\%), arthritis began before psoriasis in 6 individuals (10\%), and both psoriasis and arthritis coincided in 8 (13.3\%) patients. Obesity (OR 7.0, 95\% Cl: 2.61-18.85), nail psoriasis (OR 5.02, 95\% Cl: 2.02-12.476), and intergluteal cleft site (OR 12.659, $95 \% \mathrm{Cl}: 4.302-37.255)$ were associated with increased risk of PsA. However, classic plaque psoriasis (OR 0.149, 95\% Cl: 0.051-0.433) and flexure site (OR 0.238, 95\% Cl: 0.076-0.746) were linked with a decreased risk of PsA development.

Conclusions: Screening for PsA in patients with psoriasis revealed a significant number of undiagnosed cases of PsA that should be treated early. Obesity, nail psoriasis, and psoriasis at the intergluteal sites can help predict the PsA development.
\end{abstract}

Key words: psoriatic arthritis, psoriasis, prevalence, clinical predictors.

\section{Introduction}

Psoriatic arthritis (PSA) was classified as spondyloarthritides in the 1970s because of its resemblance to ankylosing spondylitis and reactive arthritis [1, 2].

Psoriatic arthritis is an inflammatory disease that affects skin and nails, as well as causing peripheral and axial joints, enthesitis, and dactylitis [3]. Skin psoriasis manifests ten years before joint inflammation in $85 \%$ of cases [4]. Thus, dermatologists are usually the first physicians who encounter the development of the PsA's initial manifestations. The early diagnosis and treatment help to avoid further joint involvement and disabilities. There is a problem in the early diagnosis of PsA worldwide, which may be attributed to the dermatologists missing PsA symptoms and signs and a lack of effective screening

Address for correspondence:

Mervat Eissa, Rheumatology Department, Cairo University, 1 Kasr Alainy St., 15561 Cairo, Egypt, e- mail: mervateissa@kasralainy.edu.eg Submitted: 18.08.2021; Accepted: 03.12.2021 
tools. To know the risk of PsA development, a close collaboration between rheumatologists and dermatologists with expertise in psoriatic disease is needed [5].

This issue is more pronounced in developing countries, particularly those in the Middle East and Africa. A group of experts recommends starting multidisciplinary clinics involving both specialties (Rheumatology and Dermatology) for early diagnosis, treatment, and management of PsA in Africa and the Middle East countries [6].

This study aims to establish the prevalence of PSA in psoriasis patients attending the dermatology clinic, identify the problem of underdiagnosis of PsA, and determine the clinical predictors of PsA development.

\section{Material and methods}

The authors conducted a cross-sectional observational study on 200 patients diagnosed with psoriasis (Ps) who visited the dermatology outpatient clinic Kasr Alainy Hospital, Cairo University. The data were collected from all patients who attended the dermatology clinic between December 2016 and December 2017 including a pediatric group. The studied group included in total 200 psoriasis patients, $51 \%(n=102)$ female and $49 \%(n=98)$ male. There were 22 pediatric psoriasis patients, who made up $11 \%$ of total enrolled patients; among them $59 \%$ were female $(n=13)$ and $41 \%$ were male $(n=9)$.

The age range for all participants was 5-75 years, with a median of 44 years, and the psoriasis disease $\mathrm{du}$ ration ranged between 0.08 and 45 years, with a median of 7 years. Psoriasis was diagnosed between the ages of 0.2 and 74 years, with a median of 31 years.

All procedures performed in this study followed the 1964 Helsinki Declaration and its later amendments.

The approval of the Bioethics Committee at the University of Cairo was obtained and all adult patients enrolled in the study agreed to participate and provided written consent. Informed consent on examining the pediatric patients was obtained from parents or guardians in accordance with legal standards.

\section{Assessment of psoriasis patients}

History taking and examination were done, including site, type, and extent of psoriasis. For estimating the body surface area (BSA) of psoriatic lesions, the rule of nines was used: $9 \%$ coverage for the head and neck, 9\% for each arm, 9\% for the anterior and posterior legs, and $9 \%$ for each of the 4 trunk quadrants, leaving $1 \%$ for the genitalia [7].

The severity of psoriasis was determined by employing BSA, using the following scoring: < $3 \%$ mild case of psoriasis, $3-10 \%$ moderate case of psoriasis, and $>10 \%$ severe case of psoriasis [8]. The psoriasis area and se- verity index (PASI) combines the severity and percentage of the affected area into a single score ranging from 0 (i.e., no disease) to 72 (i.e., maximal disease) [9].

The psoriasis disability index (PDI) was calculated for assessing functional lifestyle disabilities. The psoriasis disability index is a 15 -item scale. The item scores are summed to a total score with a range of 0-45 [10].

\section{Screening all psoriasis patients for psoriatic arthritis}

All psoriasis patients were screened for PsA using the following methods:

- the Psoriasis Epidemiology Screening Tool (PEST) is composed of 5 questions and a drawing of a mannequin, Yes and No answers take scores of 1 and 0 , respectively, and if the total score $\geq 3$, it is positive [11],

- the Early Arthritis for Psoriatic Patients (EARP) questionnaire consists of 10 questions, Yes and No answers receive scores of 1 and 0 , respectively, while a score of $\geq 3$ indicates a positive response [12],

- the patients with a positive PEST and/or EARP result were assessed for fulfilling the classification for psoriatic arthritis (CASPAR) criteria, indicating inflammation in the joints, spine, or entheses with $\geq 3$ points from 5 categories [13].

\section{Clinical assessment of patients with psoriatic arthritis}

Full history and examination were performed for all PsA patients.

\section{Assessment of comorbidities in psoriasis and psoriatic arthritis patients}

Assessment of comorbidities in psoriasis and PsA patients through:

- medical history of diabetes mellitus, hypertension, cardiac diseases such as ischemic heart disease (IHD), chest disease such as chronic obstructive pulmonary disease (COPD), malignancy, and hepatitis C virus (HCV) infection was taken from all patients,

- examination: calculating body mass index (BMI) and waist circumference measurement were done for all patients,

- blood tests were done for all patients including: serum uric acid, total cholesterol, triglyceride, low-density lipoprotein, high-density lipoprotein, fasting, 2 hour postprandial, and HCV antibodies by enzyme-linked immunosorbent assay.

\section{Statistical methods}

Variables such as age, gender, duration of psoriasis, age of psoriasis onset, psoriasis types, sites, psoriasis 


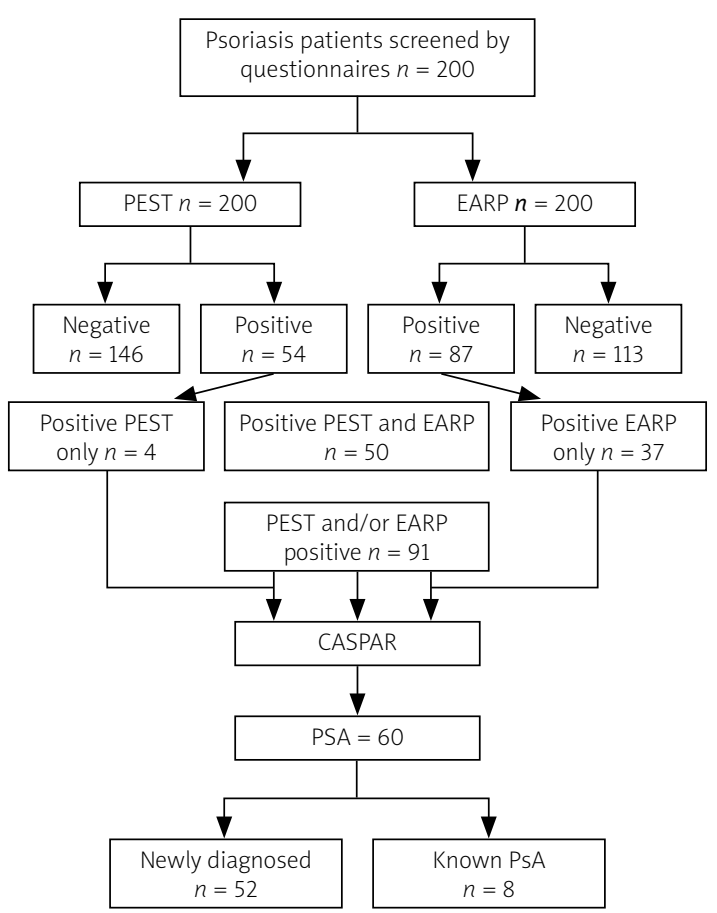

Fig. 1. Study flow chart of 200 screened psoriasis patients.

CASPAR - classification for psoriatic arthritis, EARP - Early Arthritis for Psoriatic Patients Questionnaire, PEST - Psoriasis Epidemiology Screening Tool, PSA - psoriatic arthritis.

severity, and obesity were analyzed in multivariate analysis to detect predictors of PSA in patients with psoriasis.

Data were coded and entered using SPSS version 25. Data were summarized using mean, standard deviation, median, minimum and maximum in quantitative data. The frequency (number) and relative frequency (percentage) were calculated for categorical data. Comparisons between quantitative variables were performed using the non-parametric Mann-Whitney $U$ test $[14,15]$ The chi-square $\left(\chi^{2}\right)$ test was used to compare categorical data. The exact test was performed instead when the expected frequency was less than $5[16,17]$. If the $p$-value $\leq 0.05$, it is deemed significant.

\section{Results}

The total number of patients with a positive PEST questionnaire (score $\geq 3$ ), suggestive of PsA, was 54, while the total number of patients with a positive EARP questionnaire (score $\geq 3$ ), suggestive of PsA, was 87 (Fig. 1). There were 50 patients with both EARP and PEST positive. There were 91 patients who were positive for PEST and/or EARP, and they were assessed for the fulfilment of CASPAR criteria; 60 patients were classified as having PsA. Psoriatic arthritis was found in 60 patients (30\%) with psoriasis; $8 / 60$ patients (13.4\%) were previously diagnosed with PsA.
The demographic and clinical characteristics of 60 PsA patients are summarized in Table I. The following are the comorbidities found in patients with arthritis in descending order: dyslipidemia 39 (65\%), obesity 34 (56.7\%), metabolic syndrome 29 (48.5\%), hypertension 20 (33.3\%), diabetes mellitus 15 (25\%), smoking 15 (25\%), IHD 9 (15\%), HCV infection 6 (10\%), COPD 4 (6.7\%), malignancy 2 (3.3\%) patients; one had lymphoma and the other had rhabdomyosarcoma.

Table II compares the demographics, clinical features, extent, psoriasis severity by PASI, and quality of life by PDI of PSA patients with non-PsA patients. It was found that patients with PSA had statistically significantly longer disease duration $(p=0.002)$ and lower frequency of classic plaque $(p=0.008)$. However, patients with PsA had statistically significantly higher frequency of nail psoriasis $(p<0.001)$ and erythrodermic psoriasis ( $p=0.018$ ) types. Regarding the site of psoriasis, PsA had a statistically significantly higher frequency of involvement of the knees $(p=0.008)$, genitalia $(p<0.001)$, flexure $(p=0.033)$, and intergluteal cleft $(p<0.001)$.

The prevalence of comorbidities (hypertension, diabetes mellitus, obesity, ischemic heart disease, COPD, $\mathrm{HCV}$ infection, and malignancy) was compared between patients with PSA (60) and without PsA (140). As shown in Table III, patients with PsA had a significantly increased incidence of diabetes mellitus ( $p=0.039)$, COPD ( $p=0.029)$, obesity ( $p=0.04)$, and metabolic syndrome $(p=0.004)$.

\section{Psoriatic arthritis predictors}

Obesity (OR 7.0, 95\% Cl: 2.61-18.85), nail psoriasis (OR 5.02, 95\% Cl: 2.02-12.476), and intergluteal cleft site with psoriatic changes (OR 12.659, 95\% Cl: 4.302-37.255) were associated with an elevated risk of PsA. However, classic plaque psoriasis (OR 0.149, 95\% Cl: 0.051-0.433) and flexure site (OR 0.238, 95\% Cl: 0.076-0.746) were linked with decreased risk of PsA (Table IV).

\section{Discussion}

In this study, the prevalence of PsA was 30\%, with a mean age of $45.48 \pm 10.79$ years. Further, psoriasis preceded the onset of PSA in 46 (76.6\%) patients, arthritis occurred before psoriasis in $6(10 \%)$ patients, and both psoriasis and arthritis occurred simultaneously in 8 (13.3\%) patients.

According to a recent meta-analysis, the prevalence of PsA in the general population is about $0.13 \%$ [18]. Another meta-analysis of the prevalence of PsA among skin psoriasis patients included 266 studies and 976,408 patients with psoriasis. The pooled percentage of PsA was $19.7 \%$. On the other hand, a study using 
the CASPAR found a prevalence of PSA of 23.8\% [19]. The present results showed a $30 \%$ prevalence of PsA.

This finding was consistent with a previous Egyptian study [20], although different criteria for diagnosis were used. In that study, 100 psoriasis patients were examined for PSA, which was diagnosed by the presence of joint symptoms, absence of rheumatoid nodules, negative rheumatoid factor, and any radiological manifestations. It was found that $32.0 \%$ of the patients had PsA. An earlier Egyptian study [21] was conducted on 276 psoriasis patients who attended the dermatology clinic for a year. They were examined for the presence of clinical arthritis, but no arthritis was found. A previous study gathered 82 psoriasis patients over a 6-month period from 3 dermatology centers in El Minia, Egypt [22]. The study screened patients with PsA using unique sets of criteria. The patients were considered to have PsA if they had clinical or radiological arthritis, spondylitis, enthesopathy, dactyl, or osteoperiostitis. According to these sets of criteria, they found a higher prevalence of PsA, with a rate of $72.8 \%$ (59 patients).

In comparison with different regions worldwide, our results were compatible with several European studies; for example, one study [23] found a 30\% prevalence of PsA in 949 psoriasis patients from Europe and South America. Moreover, Henes et al. [24] documented a 30\% prevalence of PsA in 404 patients with psoriasis in Germany (multicenter study). In a similar Turkish hospital-based study, 32 patients (25.4\%) out of 126 psoriasis patients had PSA [25]. Moreover, Ranza et al. [26] reported a prevalence of $33 \%$ of PsA in a large number of Brazilian psoriasis patients.

Regarding the studies in Asian countries, we found lower prevalence ranging from $1 \%$ [27] to $11 \%$ [28] among psoriasis patients. This variation may be due to specific geographical characteristics of the disease and genetic differences.

A 12-study systematic review found that the prevalence of undiagnosed PSA among psoriasis patients ranged from 4.2 to $33.6 \%$. In the meta-analysis of all 12 studies, the estimated prevalence of PsA was 15.5\% [29]. There have been studies with very similar results to the current one; for instance, research in Ireland found that $29 \%$ of psoriasis patients followed up at dermatological clinics had undiagnosed PsA [30], another study [12] in Italy reported a frequency of $31 \%$, and a study [31] in America found a prevalence of 33\%.

This prevalence result suggests that psoriasis patients should be completely assessed for PsA presence and highlights the importance of screening tests in dermatology practice, reflecting the importance of the multidisciplinary clinic (Dermatology-Rheumatology clinic). However, the logistics of this clinic and the unavailability of concerned
Table I. Demographic, clinical characteristics of psoriatic arthritis patients

\begin{tabular}{|c|c|}
\hline Patients' characteristic $(n=60)$ & Value \\
\hline \multicolumn{2}{|l|}{ Gender [years, mean \pm SD (range)] } \\
\hline Female $[n(\%)]$ & $36(60)$ \\
\hline Male $[n(\%)]$ & $24(40)$ \\
\hline Age [years, mean \pm SD] & $45.48 \pm 10.79$ \\
\hline Age of onset of PsA [years, mean \pm SD (range)] & $40.55 \pm 10.89$ \\
\hline Duration of PsA [years, median \pm SD (range)] & $3(0.5-25)$ \\
\hline $\begin{array}{l}\text { Age of onset of psoriasis [years, mean } \pm \text { SD } \\
\text { (range)] }\end{array}$ & $30.27 \pm 14.5$ \\
\hline Duration of psoriasis [years, median (range)] & $10(0.08-45)$ \\
\hline Psoriasis preceded arthritis [ $n(\%)]$ & $46(76.6)$ \\
\hline Arthritis preceded psoriasis $[n(\%)]$ & $6(10)$ \\
\hline $\begin{array}{l}\text { Psoriasis and arthritis occurred simultaneously } \\
{[n(\%)]}\end{array}$ & $8(13.3)$ \\
\hline \multicolumn{2}{|l|}{ Psoriasis types } \\
\hline Classic plaque $[n(\%)]$ & $43(71.7)$ \\
\hline Nail psoriasis $[n(\%)]$ & $43(71.7)$ \\
\hline Scalp psoriasis $[n(\%)]$ & $39(65)$ \\
\hline Erythrodermic $[n(\%)]$ & $11(18.3)$ \\
\hline Flexura $[n(\%)]$ & $7(11.7)$ \\
\hline Guttate $[n(\%)]$ & $3(5)$ \\
\hline Palmoplantar psoriasis [ $n(\%)]$ & $3(5)$ \\
\hline Pustula $[n(\%)]$ & $2(3.3)$ \\
\hline Chronic palmoplantar pustulosis [n (\%)] & $1(1.7)$ \\
\hline Extent of psoriasis (median, range) & $17.50(0.2-97)$ \\
\hline PASI (median, range) & $6.05(0.20-49)$ \\
\hline \multicolumn{2}{|l|}{ Level of severity by PASI } \\
\hline Mild $(<10)[n(\%)]$ & $33(55)$ \\
\hline Moderate to severe $(\geq 10)[n(\%)]$ & $27(45)$ \\
\hline PDI (median, range) & $13(0-34)$ \\
\hline
\end{tabular}

$P A S I-p$ soriasis area and severity index, $P D I$ - psoriasis disability index, PSA - psoriatic arthritis.

dermatologists, nurses, and clinic organizers are still restrictive factors in the Middle East and Africa [6].

Comparing psoriasis patients with and without PSA in univariate analysis, it was found that patients with PSA had statistically significantly longer disease duration $(p=0.002)$. This finding corroborated a recent population-based study, revealing that PsA incidence was associated with a longer disease duration of psoriasis ( $p=0.0001)$ [32]. Patients with PsA showed a highly significant reduction in the frequency of classic plaque $(p=0.008)$.

The following was the frequency of comorbidities found in patients with arthritis in descending order: 
Table II. Comparison of demographic and clinical characteristics between psoriatic arthritis and non-psoriatic arthritis patients

\begin{tabular}{|c|c|c|c|c|c|}
\hline Parameters & \multicolumn{2}{|c|}{ PsA $(n=60)$} & \multicolumn{2}{|c|}{ Non-PsA $(n=140)$} & $p$-value \\
\hline Age [years] (mean $\pm S D)$ & \multicolumn{2}{|c|}{$45 \pm 10.79$} & \multicolumn{2}{|c|}{$40.70 \pm 19.5$} & 0.07 \\
\hline \multicolumn{6}{|l|}{ Gender } \\
\hline Female & 36 & $40 \%$ & 66 & $60 \%$ & 0.10 \\
\hline Male & 24 & $60 \%$ & 74 & $40 \%$ & \\
\hline Psoriasis duration (median; range) & 10 & $0.08-45$ & 6 & $0.08-44$ & $0.002^{*}$ \\
\hline \multicolumn{6}{|l|}{ Type } \\
\hline Classic plaque & 43 & $71.7 \%$ & 122 & $87.1 \%$ & $0.008^{*}$ \\
\hline Scalp psoriasis & 39 & $65 \%$ & 76 & $54.3 \%$ & 0.160 \\
\hline Nail & 43 & $71.7 \%$ & 43 & $30.7 \%$ & $<0.001^{*}$ \\
\hline Guttate & 3 & $5.0 \%$ & 16 & $11.4 \%$ & 0.155 \\
\hline Inverse & 7 & $11.7 \%$ & 20 & $14.3 \%$ & 0.619 \\
\hline Erythrodermic & 11 & $18.3 \%$ & 10 & $7.1 \%$ & $0.018^{*}$ \\
\hline Pustular & 2 & $3.3 \%$ & 5 & $3.6 \%$ & 1 \\
\hline Chronic palmoplantar pustulosis & 1 & $1.7 \%$ & 1 & $0.7 \%$ & 0.511 \\
\hline Palmoplantar & 3 & $5 \%$ & 17 & $12.1 \%$ & 0.123 \\
\hline \multicolumn{6}{|l|}{ Site } \\
\hline Scalp & 48 & $80 \%$ & 95 & $67.9 \%$ & 0.081 \\
\hline Face & 13 & $21.7 \%$ & 25 & $17.9 \%$ & 0.529 \\
\hline Neck & 14 & $23.3 \%$ & 30 & $21.4 \%$ & 0.766 \\
\hline Trunk & 36 & $60 \%$ & 80 & $57.1 \%$ & 0.708 \\
\hline$U L$ & 47 & $78.3 \%$ & 106 & $75.7 \%$ & 0.689 \\
\hline LL & 46 & $76.7 \%$ & 107 & $76.4 \%$ & 0.971 \\
\hline Palms & 15 & $25 \%$ & 28 & $20.0 \%$ & 0.430 \\
\hline Soles & 13 & $21.7 \%$ & 26 & $18.6 \%$ & 0.613 \\
\hline Elbows & 32 & $53.3 \%$ & 67 & $47.9 \%$ & 0.478 \\
\hline Knees & 40 & $66.7 \%$ & 69 & $49.3 \%$ & $0.024^{*}$ \\
\hline Genitalia & 23 & $38.3 \%$ & 21 & $15 \%$ & $<0.001^{*}$ \\
\hline Flexures & 21 & $35 \%$ & 29 & $20.7 \%$ & $0.033^{*}$ \\
\hline Intergluteal cleft & 32 & $53.3 \%$ & 24 & $17.1 \%$ & $<0.001^{*}$ \\
\hline Extent [\%] (median; range) & 17.5 & $0.2-97$ & 16 & $0.1-95$ & 0.602 \\
\hline PASI (median; range) & 6.05 & $0.2-49$ & 8.1 & $10-54$ & 0.417 \\
\hline PDI (median; range) & 13 & $0-34$ & 9 & $0-53$ & $0.024^{*}$ \\
\hline
\end{tabular}

$L L$ - lower limb, PASI - psoriasis area and severity index, PDI - psoriasis disability index, PSA - psoriatic arthritis, UL - upper limb. ${ }^{*}$-value is significant $(<0.05)$.

dyslipidemia 39 (65\%), obesity 34 (56.7\%), metabolic syndrome 29 (48.5\%), hypertension $20(33.3 \%)$, diabetes mellitus 15 (25\%), smoking 15 (25\%) IHD 9 (15\%), HCV 6 (10\%), COPD 4 (6.7\%) and malignancy 2 (3.3\%) (one had lymphoma and the one patient had rhabdomyosarcoma). We found that patients with PSA had statistical significant higher incidence of diabetes mellitus $(p=0.039)$, obesity $(p=0.04)$, metabolic syndrome $(p=0.004)$, and $\operatorname{COPD}(p=0.029)$.
Husted et al. [33] documented a high prevalence of hypertension, dyslipidemia, diabetes mellitus, and CVD in PsA compared to non-PsA patients [33]. A larger number of PsA ( $n=1952)$ had more hypertension compared to psoriasis patients (over 20,000) [34].

It is widely recognized that metabolic syndrome is more prevalent in PsA than in other rheumatic disorders. However, a few research has been conducted to determine its prevalence compared to psoriasis with- 
Table III. Comparison of comorbidities between patients with psoriatic arthritis and non-psoriatic arthritis

\begin{tabular}{|lccccc|}
\hline Parameters & \multicolumn{2}{c}{ PsA $(n=60)$} & \multicolumn{2}{c}{ Non-PsA $(n=140)$} & \multirow{2}{*}{$p$-value } \\
\cline { 2 - 5 } & Count & $\%$ & Count & $\%$ & 0.152 \\
\hline Hypertension & 20 & 33.3 & 33 & 23.6 & $0.039^{*}$ \\
\hline Diabetes mellitus & 15 & 25.0 & 18 & 12.9 & $0.029^{*}$ \\
\hline COPD & 4 & 6.7 & 1 & 0.7 & 0.052 \\
\hline IHD & 9 & 15.0 & 9 & 6.4 & $0.043^{*}$ \\
\hline Obesity & 34 & 56.7 & 56 & 53.4 & 0.057 \\
\hline Dyslipidemia & 39 & 65 & $39 / 73$ & 25.3 & $0.004^{*}$ \\
\hline Metabolic syndrome & 29 & 48.3 & $21 / 83$ & 0.7 & 0.511 \\
\hline Malignancy & 1 & 1.7 & 1 & 9.3 & 0.875 \\
\hline HCV & 6 & 10.0 & 13 & 29.3 & 0.536 \\
\hline Smoking & 15 & 25.0 & 41 & & \\
\hline
\end{tabular}

COPD - chronic obstructive pulmonary disease, HCV - hepatitis C virus, IHD - ischemic heart disease, PSA - psoriatic arthritis. ${ }^{*} p$-value is significant $(<0.05)$.

Table IV. Logistic regression of independent predictors of psoriatic arthritis

\begin{tabular}{|lccccc|}
\hline Parameters & \multirow{2}{*}{$p$-value } & OR & \multicolumn{2}{c|}{$95 \% \mathrm{Cl}$} \\
\cline { 3 - 6 } & & & Lower & Upper \\
\hline Arthritis (dependent) & Classic plaque psoriasis & $<0.001^{*}$ & 0.149 & 0.051 & 0.433 \\
\cline { 2 - 6 } & Nail psoriasis & $0.001^{*}$ & 5.020 & 2.020 & 12.476 \\
\cline { 2 - 6 } & Flexures & $0.014^{*}$ & 0.238 & 0.076 & 0.746 \\
\hline & Intergluteal cleft & $<0.001^{*}$ & 12.659 & 4.302 & 37.255 \\
\hline & Obesity & $<0.001^{*}$ & 7.024 & 2.617 & 18.854 \\
\hline
\end{tabular}

$O R$ - odds ratio. * $p$-value is significant $(<0.05)$

out PsA [35]. We found that the incidence of metabolic syndrome is statistically significant higher in PsA than in non-PsA psoriasis patients. Therefore, the presence of arthritis might have a cause-effect relationship with the metabolic status.

The current results are consistent with those of Wilson et al. [36], demonstrating that scalp lesions, nail changes, and intergluteal/perianal lesions were significantly associated with a higher risk of arthritis. The risk of arthritis was 3.89-fold higher among patients with scalp psoriasis (HR 3.89, 95\% Cl: 2.18-6.94) than those without scalp lesions. In addition, psoriasis patients with nail dystrophy were threefold more likely to develop arthritis (HR 2.93, 95\% Cl: 1.68-5.12) than patients without nail dystrophy. Psoriasis patients with intergluteal/perianal lesions (HR 2.35, 95\% Cl: 1.32-4.19) had a 2.35-fold increased incidence of PsA compared to patients without these skin lesions.

Haroon et al. [30] performed a study on 100 consecutive psoriasis patients attending the dermatology clinic. The patients were assessed by 3 questionnaires and subsequently diagnosed with PSA using CASPAR criteria. A prevalence of $29 \%$ of newly diagnosed PSA among psoriasis patients was found. The clinical and demo- graphic characteristics were investigated by univariate and multivariate analysis to detect predictors of PsA. The analysis showed that newly diagnosed PsA patients had more aggressive skin involvement as evaluated by PASI. There was no significant difference regarding age, sex, drugs used for treating psoriasis, duration of psoriasis, scalp, and nail involvement.

Ranza et al. [26] reported that when psoriasis patients with and without arthritis were compared on demographic and clinical parameters (psoriasis types and PASI), PSA incidence in psoriasis patients was mostly associated with older age and nail involvement. Interestingly, a multivariate regression model applied to those variables showed that male gender was a protective factor for PsA (OR 0.416, 95\% Cl: 0.201-0.861, $p=0.018$ ), with no other predictors.

The present findings suggest that obesity is a predictor of PsA, which is consistent with a general population study conducted in the UK, reporting that obesity is accompanied by a higher risk of PsA and emphasizing the importance of weight control among psoriasis patients who have metabolic syndrome and obesity. The higher the $\mathrm{BMI}$ is, the greater is the prevalence of PsA in psoriasis patients. Compared with psoriasis patients with BMI 
$<25 \mathrm{~kg} / \mathrm{m}^{2}$, the relative risk values for developing PsA were 1.09 (0.93-1.28) for BMls of 25.0-29.9, 1.22 (1.02-1.47) for BMIs of 30.0-34.9, and 1.48 (1.20-1.81) for BMIs $\geq 35$ [37].

A population-based study in the USA showed a categorized positive association between weight change in adults, measures of central obesity, and risk of PsA $(p<0.001)$. The analysis of psoriasis development during follow-up demonstrated a close association $(p<0.01)$, indicating that a higher risk of PsA is linked with obesity among psoriasis patients [38].

Concerning nail lesions as a predictor of PsA, of all the clinical data examined so far to predict PsA, the most powerfully associated has certainly been nail disease. In a recently published study by Gisondi [39] the findings supported PsA nail involvement as a predictor of PsA development. An earlier study that intended to identify the clinical impact of nail involvement in 661 psoriasis patients showed an association between nail dystrophy and PSA, with an OR of 3.25 (95\% Cl: 2.16-4.90) [40].

Concerning medications used in psoriasis treatment and their impact on PsA development, it was found that treating patients with psoriasis with biologics might reduce the risk of developing PsA [41].

The main limitation of the present study was the small sample size, where we tried to recruit all psoriasis patients followed up in dermatology clinics during one year, but we could not.

\section{Conclusions}

Thirty percent of the patients with psoriasis had PsA, and among them $86.6 \%$ were undiagnosed, reflecting a high percentage of undiagnosed PsA that missed the early diagnosis in the dermatology clinic.

Clinicians should be aware that certain clinical features such as obesity, nail psoriasis, and intergluteal cleft site involvement in psoriatic patients might be associated with an increased risk of PsA development.

The joint Dermatology-Rheumatology clinic is the optimal solution for patients with psoriasis and PsA to improve care for this patients and minimalize disease consequences.

The authors declare no conflicts of interest.

\section{References}

1. Blumberg BS, Bunim JJ, Calkins E, et al. ARA nomenclature and classification of arthritis and rheumatism (tentative). Arthritis Rheum 1964; 7: 93-97. DOI: 10.1002/art.1780070113.

2. Moll JMH, Wright V. Psoriatic arthritis. Semin Arthritis Rheum 1973; 3: 55-78, DOI: 10.1016/0049-0172(73)90035-8.
3. Cuchacovich R, Perez-Alamino R, Garcia-Valladares I, Espinoza LR. Steps in the management of psoriatic arthritis: a guide for clinicians. Ther Adv Chronic Dis 1973; 3: 259-269, DOI: $10.1177 / 2040622312459673$.

4. Gladman DD, Antoni C, Mease P, et al. Psoriatic arthritis: epidemiology, clinical features, course, and outcome. Ann Rheum Dis 2005; 64 (Suppl 2): ii 14-17, DOI: 10.1136/ ard.2004.032482.

5. Scher JU, Ogdie A, Merola JF, Ritchlin C. Preventing psoriatic arthritis: focusing on patients with psoriasis at increased risk of transition. Nature Rev Rheumatol 2019; 15: 153-166, DOI: 10.1038/s41584-019-0175-0.

6. Bedaiwi M, Al-Homood IA, El-Garf A, et al. Disease burden and treatment challenges of psoriatic arthritis in Africa and the Middle East. Rheumatol Int 2019; 39: 1321-1329, DOI: 10.1007/s00296-019-04319-3.

7. Ramsay B, Lawrence CM. Measurement of involved surface area in patients with psoriasis. Br J Dermatol 1991; 124: 565-570, DOI: 10.1111/j.1365-2133.1991.tb04952.x.

8. Pariser DM, Bagel J, Gelfand JM, et al. National Psoriasis Foundation clinical consensus on disease severity. Arch Dermatol 2007; 143: 239-242, DOI: 10.1001/archderm.143.2.239.

9. Fredriksson T, Pettersson U. Severe psoriasis-oral therapy with a new retinoid. Dermatologica 1978; 157: 238-244, DOI: 10.1159/000250839.

10. Finlay AY, Coles EC. The effect of severe caries on the quality of life of 369 patients. Br J Dermatol 1995; 132: 236-244, DOI: 10.1111/j.1365-2133.1995.tb05019.x.

11. Ibrahim GH, Buch MH, Lawson C, et al. Evaluation of an existing screening tool for psoriatic arthritis in people with psoriasis and the development of a new instrument: the Psoriasis Epidemiology Screening Tool (PEST) Questionnaire. Clin Exp Rheumatol 2009; 27: 469-474.

12. Tinazzi I, Adami S, Zanolin EM, et al. The early psoriatic arthritis screening questionnaire: a simple and fast method for the identification of arthritis in patients with psoriasis. Rheumatology (Oxford) 2012; 51: 2058-2063, DOI: 10.1093/rheumatology/kes187.

13. Taylor W, Gladman D, Helliwell P, et al. Classification criteria for psoriatic arthritis: development of new criteria from a large international study. Arthritis Rheum 2006; 54: 26652673, DOI: 10.1002/art.21972.

14. Chan YH. Biostatistics102: Quantitative Data - Parametric and Non-parametric Tests. Singapore Med J 2003; 44: 391-396.

15. Chan YH. Biostatistics 103: Qualitative Data - Tests of Independence. Singapore Med J 2003; 44: 498-503.

16. Chan YH. Biostatistics 104: Correlational Analysis. Singapore Med J 2003; 44: 614-619.

17. Galen RS. Predictive values and efficiency of laboratory testing. Pediat J Clin North Am 1980; 27: 861-869, DOI: 10.1016/ s0031-3955(16)33930-x.

18. Scotti L, Franchi M, Marchesoni A, Corrao G. Prevalence and incidence of psoriatic arthritis: a systematic review and meta-analysis. Semin Arthritis Rheum 2018; 48: 28-34, DOI: 10.1016/j.semarthrit.2018.01.003.

19. Alinaghi F, Calov M, Kristensen LE, et al. Prevalence of psoriatic arthritis in patients with psoriasis: a systematic review and meta-analysis of observational and clinical studies. 
J Am Acad Dermatol 2019; 80: 251-265e19, DOI: 10.1016/j. jaad.2018.06.027

20. El-Moselhy EA, Nada IS, Khalifa HO, et al. Psoriasis and psoriatic arthritis: characteristics and risk factors among adult patients in Egypt. Egypt J Hosp Med 2012; 47: 301-320, DOI: 10.21608/ejhm.2012.16299.

21. El Din Bahgat N, Fattah A. Psoriatic arthritis in Egypt. Dermatologica 1967; 134: 135-151.

22. Sadek HA, Abdel-Nasser AM, El-Amawy TA, Hassan SZ. Rheumatic manifestations of psoriasis. Clin Rheumatol 2007; 26 488-498, DOI: 10.1007/s10067-006-0307-1.

23. Mease PJ, Goffe BS, Metz J, et al. Etanercept in the treatment of psoriatic arthritis and psoriasis: a randomized trial. Lancet 2000; 356: 385-390, DOI: 10.1016/S0140-6736(00)02530-7.

24. Henes JC, Ziupa E, Eisfelder M, et al. High prevalence of psoriatic arthritis in dermatological patients with psoriasis: a cross-sectional study. Rheumatol Int 2014; 34: 227-234, DOI: 10.1007/s00296-013-2876-z.

25. Çinar N, Bodur H, Filiz E, et al. The prevalence and characteristics of psoriatic arthritis in patients with psoriasis in a tertiary hospital. Arch Rheumatol 2015; 30: 23-27, DOI: 10.5606/ ArchRheumatol.2015.4454.

26. Ranza R, Carneiro S, Qureshi A, et al. Prevalence of psoriatic arthritis in a large cohort of Brazilian patients with psoriasis. J Rheumatol 2015; 42: 829-834, DOI: 10.3899/jrheum.140474.

27. Kawada A, Tezuka T, Nakamizo Y, et al. A survey of psoriasis patients in Japan from 1982 to 2001. J Dermatol Sci 2015; 31: 59-64, DOI: 10.1016/s0923-1811(02)00142-1.

28. Shin D, Kim HJ, Kim DS, et al. Clinical features of psoriatic arthritis in Korean patients with psoriasis: a cross-sectional observational study of 196 patients with psoriasis using Psoriatic Arthritis Screening Questionnaires. Rheumatol Int 2016; 36: 207-212, DOI: 10.1007/s00296-015-3365-3.

29. Villani AP, Rouzaud M, Sevrain M, et al. Prevalence of undiagnosed psoriatic arthritis among psoriasis patients: Systematic review and meta-analysis. J Am Acad Dermatol 2015; 73: 242-248, DOI: 10.1016/j.jaad.2015.05.001.

30. Haroon M, Kirby B, FitzGerald O. High prevalence of psoriatic arthritis in patients with severe psoriasis with suboptimal performance of screening questionnaires. Ann Rheum Dis 2013; 72: 736-740, DOI: 10.1136/annrheumdis-2012-201706.

31. Walsh JA, Callis Duffin K, Krueger GG, Clegg D. Limitations in screening instruments for psoriatic arthritis: a comparison of instruments in patients with psoriasis. J Rheumatol 2013; 40: 287-293, DOI: 10.3899/jrheum.120836.

32. Egeberg A, Skov L, Zachariae C, et al. Duration of psoriatic skin disease as risk factor for subsequent onset of psoriatic arthritis. Acta Derm Venereol 2018; 98: 546-550, DOI: 10.2340/00015555-2912.

33. Husted JA, Thavaneswaran A, Chandran V, et al. Cardiovascular and other comorbidities in patients with psoriatic arthritis: a comparison with patients with psoriasis. Arthritis Care Res (Hoboken) 2011; 63: 1729-1735, DOI: 10.1002/acr.20627.

34. Edson-Heredia E, Zhu B, Lefevre C, et al. Prevalence and incidence rates of cardiovascular, autoimmune and other diseases in patients with psoriatic or psoriatic arthritis: a retrospective study using Clinical Practise Research Datalink. J Eur Acad Dermatol Venereol 2015; 29: 955-963, DOI: 10.1111/jdv.12742.

35. Bostoen J, Van Praet L, Brochez L, et al. A cross-sectional study on the prevalence of metabolic syndrome in psoriasis compared to psoriatic arthritis. J Eur Acad Dermatol Venereol 2014; 28: 507-511, DOI: 10.1111/jdv.12071.

36. Wilson FC, Icen M, Crowson CS, et al. Incidence and clinical predictors of psoriatic arthritis in patients with psoriasis: a population-based study. Arthritis Rheum 2009; 61: 233-239, DOI: 10.1002/art.24172.

37. Love TJ, Zhu Y, Zhang Y, et al. Obesity and the risk of psoriatic arthritis: a population-based study. Ann Rheum Dis 2012; 71: 1273-1277, DOI: 10.1136/annrheumdis-2012-201299.

38. Li W, Han J, Qureshi AA. Obesity and risk of incident psoriatic arthritis in US women. Ann Rheum Dis 2012; 71: 1267-1272, DOI: 10.1136/annrheumdis-2011-201273.

39. Gisondi P, Bellinato F, Targher G, et al. Biological disease-modifying antirheumatic drugs may mitigate the risk of psoriatic arthritis in patients with chronic plaque psoriasis. Ann Rheum Dis 2021, DOI: 10.1136/annrheumdis-2021-219961.

40. Armesto S, Esteve A, Coto-Segura P, et al. Nail psoriasis in individuals with psoriasis vulgaris: a study of 661 patients. Actas Dermosifiliogr 2011; 102: 365-372, DOI: 10.1016/j. ad.2011.02.007 [Article in Spanish].

41. Felquer ML, LoGiudice L, Galimberti ML, et al. Treating the skin with biologics in patients with psoriasis decreases the incidence of psoriatic arthritis. Ann Rheum Dis 2021, DOI: 10.1136/ annrheumdis-2021-220865 [Online ahead of print]. 